\title{
Women Entrepreneurship in STEM fields: Literature Review and Future Research Avenues
}

\begin{abstract}
The aim of the paper is to explore the published management research on women entrepreneurs in Science, Technology, Engineering and Mathematics (also known as STEM) fields in order to offer a first, comprehensive state-of-the-art of this research. In doing so, a systematic literature review (SLR) of 32 papers has been undertaken. The results of this SLR show that the literature on this topic is still limited and fragmented. However, seeds have been sown for stimulating the theoretical debate and the empirical knowledge on these issues. Based on our analysis of these selected papers, we offer a vibrant research agenda for future developments.
\end{abstract}

\section{Keywords}

Women entrepreneurs; STEM; systematic literature review.

\section{Introduction}

Over the years, the interest in STEM (the acronym for "Science, Technology, Engineering and Mathematics") disciplines has been increasing worldwide. This is mainly because STEM knowledge is associated with a country's level of innovation and competitiveness, and social and economic growth thus, consequently, the overall level of well-being of society (OECD 2017, 2018).

In order to be competitive in the global economy, a plethora of national and supranational organisations, such as the OECD, the UN, etc., have developed programmes devoted to attracting and retaining people in STEM, with the aim of channelling knowledge investments into productivity and growth. Although such programmes address both men and women, results show that STEM fields are generally characterized by a strong gender imbalance in terms of education. In 2015, in Europe, $33.8 \%$ of male graduates obtained their degree in STEM disciplines, against $11.8 \%$ of female graduates in the same fields (European Union 2018). This gender gap in STEM education is typically ascribed to the existence of enduring gender stereotypes, based on the idea of specific gender roles and occupational gender segregation, as well as by the absence of female role models and mentoring (e.g. Smeding 2012).

One of the main consequences of this imbalance concerns employment, as the so-called "leaky pipeline" metaphor well explains ${ }^{1}$ (see Wickware 1997; Blickenstaff 2005; Martin et al. 2015).

\footnotetext{
${ }^{1}$ The "leaky pipeline" is a metaphor which explains why women in STEM fields are under-represented. As Blickenstaff (2005) explains: "This pipeline leaks students at various stages: students who express interest in science careers sometimes change their minds when applying to colleges and universities and select other areas of study. Others begin
} 
Therefore, the scant representation of women entrepreneurs within STEM fields is not surprising, as well as the fact that, consequently, the analysis of the characteristics of women entrepreneurs (and of their firms) operating in these fields has been mostly neglected in the women entrepreneurship research area until now.

Notwithstanding, we claim that a more thorough understanding of issues related to women's entrepreneurship in STEM is crucial for the following reasons. Firstly, a small number of women actually do fund and run STEM firms, and hopefully an increasing number of them could be interested in such an opportunity, therefore deserving scholars' attention. Secondly, firms established in STEM fields are an instrument to capitalize on the STEM training and talent of those women who studied these disciplines but have decided to leave bench science (Etzkowitz and Ranga 2011). Thirdly, STEM women entrepreneurs can play an important role as mentors and role models for younger women and thus push girls towards education in these fields.

Stemming from the above considerations, the purpose of this paper is to explore the published management research on women entrepreneurs in STEM fields in order to offer a comprehensive picture of the state-of-the-art of research on this issue. In doing so, a systematic literature review (SLR) of 32 papers has been undertaken. We systematically investigate and compare the selected papers along three main dimensions: the gender issue, the main topic investigated by the authors and the suggested implications, both for research and practice. As this is the first review of this issue, we strongly believe that these three dimensions are worth studying to advance our knowledge on the topic. Indeed, in relation to gender, over the years, academia has shown that entrepreneurship is not gender neutral (e.g. Ogbor 2000; De Bruin et al. 2007; Jennings and Brush 2013; Henry et al. 2015) and that technology and masculinity are profoundly connected (e.g. Carter and Kirkup 1990); therefore, it is particularly interesting to investigate if and how the experiences of entrepreneurship in STEM are gendered. Regarding the main issue investigated by the authors, what is interesting to understand is if issues and findings conflicting or coincident with previous work on women entrepreneurship do emerge. This is of interest, especially given the unique sector of activity considered, as well as the background of the investigated women entrepreneurs. Finally, as the topic is relatively new, it is interesting to analyse the research trajectories that the pioneering scholars have traced in their research and that require further investigation. Moreover, answering the numerous calls for studies that invoke the need to take a step beyond the differences between women and men entrepreneurs, by considering instead the differences among women, we distinguish between academic and non-academic women entrepreneurs. Such categorization reflects the well-established

their post-secondary education in a STEM programme, but change majors before graduation. Finally, some students leave the pipeline after graduating with a STEM degree when they select another field as a career. One interesting feature of these leaks is that women leak out more than men do" (p. 369). 
and well-recognized difference between science and mainstream entrepreneurs in academia (Rosa and Dawson 2006), the former being motivated more by their research than by profit, with higher levels of risk-aversion, and being more influenced by external forces to start an endeavour than the latter. It is, therefore, interesting to compare these two categories of women entrepreneurs in order to understand if (and, eventually, how) gender affects the way in which they are entrepreneurs, and if differences in the way they behave, manage and run their firms actually exist.

The results of this SLR show how limited and fragmented the literature on this topic still is. However, seeds have been sown for stimulating the theoretical debate and the empirical knowledge on these topics. Stemming from the selected papers, we propose a rich future research agenda for entrepreneurship scholars.

The paper is structured as follows: firstly, the SLR protocol is described. Secondly, trends emerging from research are presented. Thirdly, the main results are analysed and, lastly, conclusions, implications for future research and limitations are highlighted.

\section{Methods}

We adopted the SLR method as, according to Thorpe et al. (2005), it "assists in linking future research to the questions and concerns that have been posed by past research" (p. 258). Precisely, the word "systematic" refers to a "comprehensive accumulation, transparent analysis, and reflective interpretation of all empirical studies pertinent to a specific question" (Rousseau et al. 2008, p. 9); therefore, as this review is the first on this issue, this type of review, by adopting explicit and rigorous search and analysis procedures (Tranfield et al. 2003), is the most appropriate method.

We chose to follow the structure of prior SLRs widely recognized, in academic literature, for their scientific value, such as Newbert (2007), Thorpe et al. (2005), Tranfield et al. (2003) and Pittaway and Cope (2007). Therefore, the information collection process, the studies' selection criteria and the analysis are hereafter described.

\subsection{Information collection process}

We chose, in the search for keywords, the most comprehensive databases of peer-reviewed journals in the social sciences, namely Scopus, Web of Science (WoS) and Business Source Complete (EBSCO). All three databases were searched by requiring that the articles contain the following words in three different searching rows (Table 1$)^{2}$.

\footnotetext{
${ }^{2}$ Although no SLRs exist on the topic, the keywords have been selected by considering also Cheryan et al. (2016) for the STEM keywords; Foss et al. (2018) for gender keywords and Poggesi et al. (2016) for firm-related keywords.
} 
Table 1 about here

The search criteria and results are shown in Table 2. As our focus is to analyse management research on women entrepreneurs in STEM fields, limitations in the subject area were added for Scopus and WoS.

Table 2 about here

\subsection{Studies' selection}

To select relevant studies, the following steps were undertaken. First, duplicate articles, within and across databases, were discarded. Then, the first and second authors distributed the articles between them and reviewed titles and abstracts. In doing so, specific and clear inclusion and exclusion criteria were used to select only those articles specifically focused on women entrepreneurship within STEM fields. These criteria are shown in Tables 3 and 4.

Table 3 about here

Table 4 about here

This process excluded 4,836 papers. Such a high discarded rate is justified by the fact that a huge number of scholars dealing with women in STEM have focused their research attention on the investigation of women's education problems, rather than on women entrepreneurs' experiences in these fields; thus, according to our exclusion criteria, such papers have been discarded.

Afterwards, all the authors read the full text of all the potentially relevant articles to examine their eligibility according to the inclusion criteria depicted in Table 3. In addition, by means of the snowballing technique, the authors consolidated the research outputs. We identified three 
publications which were added to the dataset, thus 32 articles were finally considered eligible for the $\mathrm{SLR}^{3}$.

The steps described above are illustrated in Figure 1.

Figure 1 about here

\subsection{Data analysis}

With the aim of analysing the 32 selected papers, we conducted a two-step analysis. The first step consisted of a manual sorting of the papers along two main dimensions: a) each paper's keywords, and b) each paper's research question(s). In doing so, two different types of women entrepreneurs in STEM clearly emerge and such differentiation has allowed us to create two different clusters; the first cluster deals with academic women in STEM who have identified an entrepreneurial opportunity in their research disciplines to be pursued by establishing their own STEM firm. The second cluster refers to non-academic women who, for several reasons (e.g. experiencing "glass ceiling" hurdles, a high need for achievement, etc.), have decided to establish and run a STEM firm. Specifically, nine papers belong to the $1^{\text {st }}$ cluster "Academic women entrepreneurs in STEM fields" and 23 to the $2^{\text {nd }}$ cluster "Non-academic women entrepreneurs in STEM fields".

The second step of the analysis involves an in-depth content analysis of the selected 32 papers. To do this, a reading guide for the papers was established and shared among the authors; it was employed to read and analyse the articles along three main dimensions: the gender issue, the main topic investigated by the author(s) and the suggested implications, both for research and practice. The main results for the selected papers are reported in the Appendix.

\section{Trends emerging from research}

The analysis of the main trends within the selected papers shows that, regarding their publication, the number of annual papers on women entrepreneurs in STEM that appeared in peer-reviewed international management journals is discontinuous, with three main peaks. In 2010, 2012 and 2015, data show that four papers per year have been published (Fig. 2). However, if we consider the yearly

\footnotetext{
${ }^{3}$ As for the strict requirements of SLRs' research protocol, it is not out of the ordinary to find, in management literature, such a wide difference between results from the $1^{\text {st }}$ step of research and the final sample object of investigation (e.g. Abatecola et al. 2013; Osagie et al. 2016; Solnørdal and Foss 2018).
} 
involvement in terms of publication, results point to an average number of two publications per year, thus reflecting the still very scant interest of academics in this topic.

Figure 2 about here

At the overall level, 24 journals emerge as being involved in the analysed conversation; this number, together with the multidisciplinary scope of these journals, reflects the still exploratory stage of studies on STEM women entrepreneurs. Accordingly, only five journals have published more than one paper (Table 5).

Table 5 about here

Moreover, one of the 32 papers can be considered as purely theoretical, while the remaining 31 are classified as empirical studies. Of these, 18 papers use qualitative multiple research methods, mainly employing semi-structured interviews (55\%), whereas 13 papers use quantitative statistical techniques, mainly adopting regression analysis (46\%).

When the sample size is taken into account, results show that it necessarily varies on the basis of the characteristics of the empirical works considered. As far as the qualitative papers are concerned, the size of the investigated samples ranges from one observation, namely one life history analysis (Marlow and McAdam 2011), to 115 observations (Orser et al. 2012), with an average of 26 observations per paper. Although scholars are perfectly aware of the difficulties related to the generalizability of results due to a constrained number of observations, insights from these papers can however be very useful at least for two main reasons. Firstly, as they are pioneers on this issue, such papers provide the starting point for more sophisticated quantitative, as well as more in-depth qualitative, investigations. Secondly, developing a qualitative analysis on small samples can allow the researchers to really dwell on the issue they want to investigate, thus being able to gain more insights on, as an example, life histories and specific experiences strictly related to gender roles (this is the case, for example, of Marlow and McAdam 2012). With regard to the quantitative papers, what emerges is that, inevitably, the number of observations is considerably higher if compared to the qualitative papers. These numbers allow more sophisticated analyses (e.g. regression models), thus bringing the results to a wider generalization. 
Regarding the STEM fields on which the research is grounded, some information deserves particular attention. If we look at the meaning of the acronym STEM, i.e. Science, Technology, Engineering and Mathematics, results show that Technology is the most analysed field, with 50\% of selected papers dealing with women-led firms having been identified. Furthermore, almost absent is the analysis of firms in specific branches of Science; the only exceptions are two papers focused on Biotech and Chemistry, thus showing the existence of a consistent research gap.

The selected papers are also analysed according to the countries in which their research is grounded. Firstly, the analysis shows that many studies use empirical data from the US and UK (40\% of the dataset), thus mirroring a trend similar to that registered for the analysis of "classical" studies on women entrepreneurship. Secondly, research on women entrepreneurs in STEM is also gaining attention in traditionally less investigated countries such as, for example, Germany, a country analysed by four papers ( $12.5 \%$ of the dataset). The strong interest in this country can be partially explained by the latest OECD data (2017) according to which Germany has attained a leading position in education in STEM; indeed, in 2015, 40\% of first-year students in Germany's tertiary sector chose STEM subjects against the OECD average of $27 \%$.

\section{Analysis of the literature}

With the goal of offering a comprehensive picture of the state-of-the-art of research on women entrepreneurs' experiences within STEM fields, two main clusters have been identified according to the career paths of the women entrepreneurs in STEM: academic and non-academic. By systematically analysing the 32 selected papers along three dimensions, namely the gender issue, the main topic investigated by the author(s) and the suggested implications, both for research and practice, we conducted an in-depth review of the papers, the main results of which follow.

\subsection{Academic women entrepreneurs in STEM fields}

Academic entrepreneurship, also defined as the commercial application of academic research, is today a hot topic as it has become a strategic objective of universities' mission worldwide (Foss and Gibson 2015). Typical examples of academic entrepreneurship are patenting, licensing, spin-off firms, consulting and advisory firms (Klofsten and Jones-Evans 2000); however, only firms in STEM fields are considered as eligible to be analysed in this paper, according to previously identified exclusion/inclusion criteria.

The scant number of papers dealing with this topic within our dataset can be justified by an historical lack of interest in the gender dimension of academic entrepreneurship. Indeed, according to Rothaermel et al.'s (2007) review on university entrepreneurship, only one out of 173 articles 
(Thursby and Thursby 2005) analyses the gender aspect and only two articles include gender as a variable; neither has the interest shown towards women academic entrepreneurs increased over recent years. This reinforces Jennings and Brush's (2013) point, that there exists scant knowledge of women engaged in academic entrepreneurship/technology transfer.

Such lack of interest can be explained by the low rates of university entrepreneurship activities established by academic women. According to recent data, women academics are less likely than men academics to disclose their inventions (Thursby and Thursby 2005), hold a patent (Ding and Choi 2011) or establish a firm on the basis of their research (Rosa and Dawson 2006). Moreover, Abreu and Grinevich (2017) show that the gender gap among UK academics is still relevant, being equal to $6.1 \%$ for patenting, $6.8 \%$ for consultancy work, $3.9 \%$ for licensing and $3.2 \%$ for spinouts. Therefore, we consider the nine selected papers grouped in this cluster as pioneering ones as they provide new knowledge on women academics in the STEM fields.

Accordingly, most of the selected papers investigate the reasons for women academic entrepreneurs' under-representation (also in STEM fields). Generally, supply-side and demand-side explanations are proposed. With regard to the supply-side explanations, scholars first point out the over-representation of academic women in fields where spinout, patents and licensing are not common (i.e. arts and humanities). Second, the lower positions in academia occupied by women in comparison to men push the former to be firmly focused on their academic careers; added to this, it is also worth mentioning the burden of family obligations, which still emerges as one of the major reasons why women engage in academic entrepreneurship less often than men (Busolt and Kugele 2009) and, consequently, have less prior experience in managing a firm. Third, in contrast to men, women feel a strong ambivalence regarding the ethics of research commercialization (Murray and Graham 2007; Abreu and Grinevich 2017). Regarding the demand-side explanations, fewer network contacts and difficulties in raising finance are frequently cited as explanations for low academic entrepreneurship by women.

Following the above, several papers take a step further by investigating if academic entrepreneurship contributes to lower gender differences in business. Independently from comparing women and men academics' experience, or only the former, the overall analysis shows that academic entrepreneurship is unanimously considered to be a field in which some gender gaps are reduced in comparison to other activity sectors - for example women and men academics show similar levels of human capital, similar attitudes, pressure and motivation (Rosa and Dawson 2006) - thus allowing scholars to correct the sampling bias we have in traditional studies on women entrepreneurship. In line with this, Rodríguez-Gulías et al. (2018) find that firms' growth rate for women and men's university spin-offs is comparable and that the technological, human and financial resources 
positively affect growth. These results also contribute to underlining how important the academic entrepreneurship context is to reduce gender differences in business, thus enhancing the importance of investigating the role of incubators - a context able to offer services, advice, mentoring, and access to finance to entrepreneurs.

Moreover, scholars are investigating how the experience of academic entrepreneurship is gendered. Karataş-Özkan and Chell (2015), for example, find that, although male and female academic entrepreneurs share several experiences, gender inequalities exist and affect women academics' experiences. Masculinized norms and total engagement in the business characterize the context, making entrepreneurship in the field gendered. In relation to the gender discourse, the paper by Fältholm et al. (2010) is worth mentioning as these scholars call for a "feminist degendering movement" (Lorber 2000) in order to avoid reproducing gendered conceptions of the "true male academic entrepreneur".

Regarding the implications, both for research and practice, it is interesting to point out that, although cited in every paper, their level of analysis is different. On the one hand, the implications for research are often rich, articulated and able to offer interesting hints for scholars, e.g. the adoption of an intersectional approach that takes into consideration seniority and gender (Rosa and Dawson 2006) as well as age, ethnicity and career-stage (Karataş-Özkan and Chell 2015). Furthermore, there is the identification of factors that contribute to avoid gender differences in firms' growth and other performance measurement in academic entrepreneurship (Rodríguez-Gulías et al. 2018), and the analysis of ways in which "the processes, structures and discourses of academic entrepreneurship are constructed and gendered" (Fältholm et al. 2010, p. 60). On the other hand, the practical implications still appear to be general, mainly addressing the importance of improving the opportunities for women's career progression (Abreu and Grinevich 2017), and also the need to foster gender equality programmes in universities (Karataş-Özkan and Chell 2015).

\subsection{Non-academic women entrepreneurs in STEM fields}

Papers grouped under this cluster investigate the experiences of non-academic women entrepreneurs in STEM fields by mainly adopting a social constructivist perspective (e.g. Henry et al. 2015). However, most of the papers considered here take such a perspective for granted, very rarely developing an explicit analysis of the underpinnings of the gender lenses they use.

Within this context, the analysis shows that the topics analysed by the authors in the papers are particularly heterogeneous. Two comprehensive papers (Ezzedeen and Zikic 2012; Orser et al. 2012) deeply analyse the gender-related barriers STEM women entrepreneurs must face. Orser et al. (2012) 
analyse the individual, firm/organizational and industry- or institutional-level career barriers, as well as the resolution strategies to these barriers. The individual barriers are identified in the lack of educational and industry credentials, management expertise, personal conflicts associated with role investment and work/family responsibilities. Firm barriers traditionally include different access to internal resources, support structures, professional networks, mentors and power. Finally, industry barriers refer to industry culture and informal rules of behaviour. Results show that the challenges women must cope with are frequently associated with their gender, and mentoring can be considered as the most suitable strategy to overcome such barriers. On the other hand, Ezzedeen and Zikic (2012) identify an additional obstacle that women entrepreneurs must face, i.e. resistance from male financiers, male clients, and male subordinates; in particular, referring to male subordinates, the authors propose a new metaphor, i.e. "thorny floors", to describe the opposition and sabotage women entrepreneurs must face.

Three papers investigate the strategies women entrepreneurs have developed to survive and succeed in such strongly masculinized fields, and show that women have the tendency to emulate their male colleagues. In Martin et al. (2015), the interviewed women entrepreneurs cope with the above defined difficulties by striving to become an "honorary man", both in attitude and mainly via their knowledge and expertise, in order to gain professional respect. This can be read as the result of the process of assimilation (Kanter 1993, p. 211), where minority group members adopt pre-existing stereotypes as a way of reducing their visibility. The process of assimilation also emerges in the two papers by Marlow and McAdam $(2012$, 2015), which analyse the experiences of women hightechnology entrepreneurs within the context of business incubation. In particular, in the interview conducted by Marlow and McAdam (2012), the interviewed woman, rather than challenge the prevailing masculine culture, acts like the boys "to fit in", matching masculinized toughness and sexualized leverage, thus perpetuating the established culture. Such results are confirmed in Marlow and McAdam (2015) where it becomes clear that the interviewed women are ready to engage in "game playing". In line with this, one of the interviewed women entrepreneurs acclaims her (male) mentor as he was able to teach her "to think like a man" (p. 801). However, these results must be considered in light of Eriksson et al.'s (2008) paper which clearly underlines that the gendering processes and the enactments of masculine and feminine meanings have to be contextualized within the specific "business context", as diverse fields - STEM included - require different strategies.

Furthermore, several "traditional" women entrepreneurship topics are covered in the selected papers. For example, networking activities of the identified women are analysed. Over the years, the "traditional" studies have highlighted that women-owned businesses' networks are weaker, smaller and less structured than men's (e.g. Greene et al. 1999). However, several reviews of empirical 
research on gender in entrepreneurial networks verify that the empirical results do not support such hypotheses, as large differences between male and female entrepreneurs are rarely found (e.g. Foss 2010, 2017). Interestingly, similar results also emerge in relation to women entrepreneurs in STEM fields. According to Hampton et al. (2009, 2011), the approach of women entrepreneurs to networking activities changes during the firm's life cycle. At the beginning, they mostly rely on women only networks and personal contacts but, quickly, they realize that for the growth of their firm they need to enhance the levels of network quality by deliberately developing a proactive behaviour. The limited number of women entrepreneurs in the selected fields pushes women to develop mixed gender networks, connecting with people with whom they could have a high degree of trust, empathy and confidence (Hampton et al. 2009). Interestingly, Hampton et al. (2009) identify some common traits in women's behaviour, which can be seen as a way to emulate their male counterparts, in order to "better fit" with the male-dominated environment in which women work. Similar results also emerge in the study by Martin and Tiu Wright (2005), which underlines the relevance, for STEM women entrepreneurs, of relying on the use of Innovation and Communication Technologies (ICTs) to actively stimulate their networking activity, not only with other women entrepreneurs and female business associates, but also - in the most effective cases - with male dominated groups of entrepreneurs.

Another discussed issue is related to the funding entrepreneurial team. Technology-based firms (independently of the gender of the entrepreneur) work in a volatile, fast, dynamic environment (O'Connor et al. 2006), and struggle with scarcity of capital. Both technical and management skills are required, justifying entrepreneurial teams rather than single entrepreneurs as funders. What emerges from our dataset is that, at a general level, no direct correlations between demographic team heterogeneity (team size or gender) and firm performance emerge (e.g. Dautzenberg and Reger 2010). However, in this regard, the scholars' interest seems to be focused on the phenomenon of co-preneurs. Co-preneurs are defined as "couples of entrepreneurs who share ownership, commitment and responsibility for a business" (Barnett and Barnett 1988). According to O'Connor et al.'s (2006) results, within the teams, wives tend to handle more "women's work" (e.g. administration tasks) while husbands, who are most frequently recognized as the lead founders, tend to work in sales or product development. More recently, Kuschel and Lepeley (2016) point out that, for women funders, trust between the partners, rather than skills and know-how, is the main reason to work together and that strategic decisions as well as family decisions are always taken by a couple. However, most of the interviewed entrepreneurs admit that they prefer to hide the fact that the entrepreneurial team is based on their partners. 
When taking the implications for both research and practice into account, we note that almost all the papers clustered here (96\% of non-academic papers) explicitly provide implications for future research. The studies considered here suggest, as an example: 1) to obtain more insights on the characteristics of traditionally considered "masculine occupations" (e.g. Martin et al. 2015); 2) to expand the sample for the analysis; and 3) to go into more depth with specific topics, such as barriers or networking (e.g. Buche and Scillitoe 2007). In contrast, a lower number of papers pay attention to an explicit indication of future implications for practice. In this vein, studies largely underline the need to develop targeted policies able to attract and retain women in STEM fields (e.g. Orser et al. 2012) or to ensure those women have adequate financing (e.g. Alakaleek and Cooper 2018; Kuschel et al. 2017).

\section{Discussion}

The purpose of this paper is to explore the published management research on women entrepreneurs in STEM fields in order to offer the first comprehensive picture of the state-of-the-art of research on this issue.

We searched for 41 keywords in three different databases, considering management journals only. We further strictly applied seven inclusion and five exclusion criteria. The results from this SLR show that 32 papers were eligible to be included in the final dataset. Those 32 papers have been categorized into two different clusters, on the basis of the career path of the investigated women, namely academic women entrepreneurs and non-academic women entrepreneurs. These two clusters have then been systematically analysed along three directions: the gender issue, the main topic investigated by the authors and the suggested implications, both for research and practice.

The first and most relevant finding is as follows: despite the economic and social relevance of the STEM fields and the numerous national and supranational policies aimed at encouraging women to establish and run businesses in these industries, the research on the topic is still scant as only 32 papers are relevant to be finally included in our dataset. Particularly lacking is the attention given to academic women entrepreneurs in STEM - a result that basically mirrors the scant interest devoted to gender by the mainstream academic entrepreneurship studies.

The second finding is that scholars involved in the analysed conversation are largely rooted in the mainstream women entrepreneurship literature, deepening topics at least in part deriving from the well-established knowledge on the field. A number of "traditional" issues, such as networking, financing, performance, gender barriers, are indeed discussed in some of the selected papers. 
However, due to the low number of scholars involved in this discussion, the small samples available and the research fragmentation, no generalizable findings have yet been achieved. Notwithstanding, currently scholars within this field are pursuing the attempt to expand women entrepreneurship research frontiers. Specifically, they are starting to do so by contextualizing the "well established" evidence from traditional studies on women entrepreneurship (i.e. difficulties in financing, lower performance than those of men-led firms, no relevant differences in women and men entrepreneurs' networking activities, and the obstacles women must face because of gender) in a very masculine context. For this reason, strong emphasis is devoted to the role of gender. Indeed, the third finding is that entrepreneurship within STEM fields basically appears to be gendered. Due to the high masculinity associated both with the established norms and the main characteristics of STEM fields, women entrepreneurs grounded on these sectors tend to adopt behaviours that replicate those of men. In the "non-academic" cluster, keywords such as "fit in", "game role" or "honourable man" are frequently found.

The fourth finding reveals that the practical implications of the research topic are still frail. The pioneering scholars included in the dataset have worked hard to define future research directions, but the addressed implications for practice are often generic. In line with Foss et al.'s (2018) results, for example, suggestions associated with policy (e.g. legislation, taxation) are avoided. The most frequent recommendations refer to a "general" need to train women entrepreneurs and to develop role models which they are inspired to emulate. This is surprising, given the strong effort that national and supranational decision makers are making in supporting both entrepreneurship in STEM and women entrepreneurship.

Scholars within this field aim at expanding women entrepreneurship research frontiers. That being stated, and stemming from the findings above, we claim that research on women's entrepreneurship in STEM fields ought to be expanded. Echoing Ahl (2006), such expansion should move along two directions: $i$ ) broadening the adopted theoretical approaches and $i i$ ) expanding the research objectives.

Regarding the former $(i)$ : although the selected papers accept that gender is something related to what one does and not something that is merely related to what one is, they still do not explicitly delve into the gender question. There exist some important exceptions in our dataset (e.g. Marlow and McAdam 2012, 2015). However, the majority of the analysed papers, do not make explicit reference to the social construction of gender, thus missing an important opportunity to overcome the historical dichotomy between women and men. The gender problem is indeed not only exclusive to women but should also be extended to men and STEM fields represent interesting "laboratories" to verify such issues. Thus, future research should improve the analysis of the interactions among 
entrepreneurship, masculinity, femininity, and technology further, by not only investigating women entrepreneurs in STEM, but also men.

Regarding the latter, (ii): expanding the research objectives, some important topics are still not investigated and deserve more attention in future research. We find the following themes of interest for future research.

First, future research should address our limited knowledge about women STEM entrepreneurs' (growth) strategies. In the past, women entrepreneurs have been defined as not growth oriented (e.g. Orser and Hogarth-Scott 2002). However, the most current research has clearly pointed out that not being growth oriented is not only a women entrepreneurs' issue but, rather, an issue associated with small business owners in general (Jennings and Brush 2013). Would different results emerge when STEM fields are considered?

Second, the meaning of success is worth considering in future research. According to previous studies, women-led firms underperform compared to men-led ones (Du Rietz and Henrekson 2000). However, the verified differences in terms of performance between men-owned firms and womenowned firms, and the non-convergent results obtained after controlling for specific business characteristics, have been shown to be either the results of inappropriate performance measures or the scant (or absent) consideration of the non-economic results (e.g. Robb and Watson 2012). Regarding the latter, several scholars have recently claimed there is a need to define new and different measures of success that better mirror women entrepreneurs' definition of success, such as building satisfying relationships with employees and customers as well as contributing to society (e.g. Powell and Eddleston 2013). Within this framework, it could be interesting to analyse how established women entrepreneurs in STEM fields define their success and if and how such definition differs from that of men entrepreneurs. Such a comparison could be particularly effective as some of the gender differences (e.g. those associated with human capital, level of education, etc.) identified in the traditional women entrepreneurship research field are overcome when the STEM fields are considered, and this seems particularly true in the case of academic entrepreneurship. However, such analysis could go beyond the investigation of the specific STEM fields by broadening the perspective, including and comparing women entrepreneurs operating in different sectors in order to verify how the sector of activity, the women's background and their motivation affect the entrepreneur's definition of success.

Third, women entrepreneurs in STEM fields are also interesting to analyse in relation to their motivations. In this regard, one of the most well-known dichotomies in entrepreneurship research is that between opportunity and necessity motivations. Over the years, many scholars have pointed out that women are pushed into entrepreneurship through the necessity, for example, to find a more 
flexible solution to combine work and family responsibilities (necessity driven factors, e.g. McGowan et al. 2012). Nevertheless, behind the necessity motives, entrepreneurship may still also attract women through opportunity-based factors. Interestingly, still no consensus regarding which factor exerts the greatest influence has emerged yet and the most current theoretical findings clearly stress that the push/pull motives rarely exclude each other (e.g. Kirkwood 2009). Do results change if women entrepreneurs in STEM fields are considered? This research direction could benefit, at least in part, by Welter et al.'s (2017) suggestions, which call for an overcoming of this traditional “opportunity vs. necessity" dichotomy that, instead of exalting women entrepreneurs' differences, has the opposite effect of marginalizing them. Thus, as they suggest, it would be more fruitful to focus future research on the dynamics of entrepreneurship during the entrepreneur's lifetime. This seems particularly relevant in the case of women entrepreneurs in the STEM field who abandon their academic career in order to pursue an entrepreneurial one.

Fourth, the relationships with financial institutions should not be overlooked. In order to grow, both debt and equity are important. Previous research has shown that women entrepreneurs have difficulties either in seeking (i.e. "self-discriminatory" behaviour) or obtaining external financial resources (e.g. Neeley and Van Auken 2010). Most scholars have argued that this situation is the result of the business peculiarities of women-led firms, as well as the women entrepreneurs' prior experiences with the credit system. We ask: Are these problems also relevant in the case of women entrepreneurs in STEM fields?

Fifth, future research should focus on work-family conflicts experienced by women entrepreneurs. Although this topic is also under-investigated in the more traditional research on women entrepreneurship (e.g. Poggesi et al. 2017), it is generally listed as one of the main reasons for womenled firms' underperformance compared to men's firms. Future research could investigate this issue in at least three directions: firstly, analysing how women entrepreneurs in STEM fields manage the work-family interferences, by comparing their coping strategies with those developed by more traditional women entrepreneurs in order to understand if and how the sector of activity affects these interferences (Poggesi et al. 2015). Secondly, comparing work-family conflicts' coping strategies of both men and women entrepreneurs in STEM fields, in order to investigate if differences still exist. Thirdly, due to the peculiarities of the fields investigated here, particularly worth studying is also the overall level of satisfaction of these women entrepreneurs, deepening the positive spill-over from the family and its effects on women's satisfaction but also firm's performance.

Sixth, to better understand the investigated phenomenon, the context should not be overlooked. Future studies should enhance analysis of the socio-economic context in which women-led STEM firms are grounded. A more thorough understanding of a country's family and economic policy, 
labour market, social norms and culture can also be beneficial for developing comparative studies between and among different countries. Moreover, the business contexts should also be acknowledged by scholars. In all the selected papers, but one (i.e. Eriksson et al. 2008), STEM fields are identified as a homogeneous industry, without considering their specific peculiarities and characteristics. However, differences among industries and sub-fields exist and can affect the women entrepreneurs' experience and the gendering processes. Opportunities for future research are clearly present here.

Seventh, most of the studies in our dataset are based on small samples - the most suitable choice according to the most frequently adopted research methodology (i.e. interviews). Accordingly, there is a need for adopting larger samples (when possible) and, above all, longitudinal analyses. This will make it possible to identify different attitudes of women STEM entrepreneurs in the start-up, growth and exist stages (e.g. Hampton et al. 2011), and allow scholars to elaborate on more generalizable results.

Besides the above highlighted future research agenda, it is worth discussing some suggestions which may help policymakers in designing ad hoc programmes in order to support women entrepreneurship in STEM fields. Specifically, at least two levels of analysis could be expanded.

First, the educational one has to be mentioned, with specific reference to the need to develop targeted programmes that can support, starting from primary schools, the approach of girls to scientific disciplines. The aim is then to develop ad hoc tools to increase the presence of women in STEM fields (scholarships, internships, etc.) and eventually to support them in entering an entrepreneurial career after graduation or alongside an academic career. Second is that of public investments. In this vein, both the demand and supply sides of work should be taken into account in the development of targeted policies that are aimed at stimulating aspects such as funding for women enterprises in STEM fields, support for internationalization, creation of networks and partnerships with local entities for the definition of integrated development plans.

\section{Limitations}

When the limitations of this paper are taken into account, these are generally ascribable to SLRs in general, as clearly underlined by Newbert (2007) and more recently by Günzel-Jensen et al. (2014). The first limit is that the first step of the research has been conducted by searching for selected keywords in the abstract and title of articles included in, at least, one database among Scopus, WoS and EBSCO. However, it may be that these three different databases do not contain all the related 
papers. However, as these are the most comprehensive databases of peer-reviewed journals in the social sciences, we assume that the analysed abstracts best represent the overall population of the management abstracts on the topic. The second limit is that the specific keywords and rigorous criteria used in the identification of the papers have led the authors of this paper to identify the final dataset in ways that other keywords and criteria may not have. For example, we decided to limit our analysis only to management journals; however, psychology, sociology, and economic research could provide additional food for thought. Moreover, we have not considered those papers dealing with students in STEM fields; however, most research is currently on this segment and it could be interesting to understand how to foster students' entrepreneurial orientation.

\section{Conclusion}

Findings from this systematic analysis shows that the interest of management scholars in this topic is still scant. This is quite surprising, given the recognized socio-economic relevance of women entrepreneurship in this area.

In this vein, we believe that this paper's findings contribute to generate awareness concerning what is currently researched in relation to women entrepreneurs in STEM fields, stimulating both academic and practitioners' attention towards this topic. 


\section{References}

Abatecola, G., Caputo, A., Mari, M., \& Poggesi, S. (2013) Real estate management: past, present, and future research directions. International Journal of Globalisation and Small Business, 5(1/2, 98-113.

Abreu, M., \& Grinevich, V. (2017). Gender patterns in academic entrepreneurship. The Journal of Technology Transfer, 42(4), 763-794.

Ahl, H. (2006). Why research on women entrepreneurs needs new directions. Entrepreneurship Theory and Practice, 30(5), 595-621.

Alakaleek, W., \& Cooper, S. Y. (2018). The female entrepreneur's financial networks: accessing finance for the emergence of technology-based firms in Jordan. Venture Capital, 20(2), 137-157.

Bendell, B. L., Sullivan, D. M., \& Marvel, M. R. (2019). A Gender-Aware Study of Self-Leadership Strategies among High-Growth Entrepreneurs. Journal of Small Business Management, 57(1), 110-130.

Barnett, F., \& Barnett, S. (1988). Working together: entrepreneurial couples, Ten Speed Press, Berkeley, CA.

Best, K., Sinell, A., Heidingsfelder, M. L., \& Schraudner, M. (2016). The gender dimension in knowledge and technology transfer-the German case. European Journal of Innovation Management, 19(1), 2-25.

Blickenstaff, J. (2005). Women and science careers: leaky pipeline or gender filter? Gender and Education, 17(4), 369-386.

Buche, M. W., \& Scillitoe, M. L. (2007). Influence of gender and social networks on organizational learning within technology incubators. American Journal of Business, 22(1), 59-68.

Busolt, U., \& Kugele, K. (2009). The gender innovation and research productivity gap in Europe. International Journal of Innovation and Sustainable Development, 4(2-3), 109-122.

Carter, R., \& Kirkup, G. (1990). Women in professional engineering: The interaction of gendered structures and values. Feminist Review, 35(1), 92-101

Cheryan, S., Ziegler, S. A., Montoya, A. K., \& Jiang, L. (2016). Why are some STEM fields more gender balanced than others? Psychological Bulletin, 143(1), 1.

Dautzenberg, K., \& Reger, G. (2010). Entrepreneurial team characteristics and success of new technology-based firms in Germany. International Journal of Business and Globalisation, 4(1), 71-94.

De Bruin, A., Brush, C. G., \& Welter, F. (2007). Advancing a framework for coherent research on women's entrepreneurship. Entrepreneurship Theory and Practice, 31(3), 323-339. 
Ding, W., \& Choi, E. (2011). Divergent paths to commercial science: A comparison of scientists' founding and advising activities. Research Policy, 40(1), 69-80.

Du Rietz, A., \& Henrekson, M. (2000). Testing the female underperformance hypothesis. Small Business Economics, 14(1), 1-10.

Eriksson, P., Henttonen, E., \& Meriläinen, S. (2008). Managerial work and gender-Ethnography of cooperative relationships in small software companies. Scandinavian Journal of Management, 24(4), 354-363.

Etzkowitz, H., \& Ranga, M. (2011). Gender dynamics in science and technology: From the "leaky pipeline" to the "vanish box". Brussels Economic Review, 54(2/3), 131-148.

European Union, 2018, Women in the Digital Age.

Ezzedeen, S. R., \& Zikic, J. (2012). Entrepreneurial experiences of women in Canadian high technology. International Journal of Gender and Entrepreneurship, 4(1), 44-64.

Fältholm, Y., Abrahamsson, L., \& Källhammer, E. (2010). Academic entrepreneurship: gendered discourses and ghettos. Journal of Technology Management \& Innovation, 5(1), 51-63.

Foss, L. (2010). Research on entrepreneur networks: The case for a constructionist feminist theory perspective. International Journal of Gender and Entrepreneurship, 2(1), 83-102.

Foss, L. (2017). Research on networks, gender and entrepreneurship: A never changing discourse? in C. Henry, T . Nelson, \& K.V. Lewis (Eds.), The Routledge Global Companion to Female Entrepreneurship. Routledge.

Foss, L., Henry, C., Ahl, H., \& Mikalsen, G. H. (2018). Women's entrepreneurship policy research: a 30-year review of the evidence. Small Business Economics, 1-21.

Foss, L. and Gibson, D. V. (2015). The Entrepreneurial University. Context and institutional change. Routledge. London and New York.

Gicheva, D., \& Link, A. N. (2013). Leveraging entrepreneurship through private investments: does gender matter? Small Business Economics, 40(2), 199-210.

Greene, P., Brush, C., Hart, M., \& Saparito, P. (1999). Exploration of the venture capital industry: Is gender an issue? In P.D. Reynolds, W.D. Bygrave, S. Manigart, C.M. Mason, G.D. Meyer, H.J. Sapienza, \& K.G. Shaver (Eds.), Frontiers of Entrepreneurship Research (pp.168-181). Wellesley: Babson College.

Günzel-Jensen, F., Korsgaard, S., \& Müller, S. (2014). A note of caution on systematic literature reviews in entrepreneurship research. In ICSB World Conference 2014.

Hampton, A., Cooper, S., \& McGowan, P. (2009). Female entrepreneurial networks and networking activity in technology-based ventures: An exploratory study. International Small Business Journal, 27(2), 193-214. 
Hampton, A., McGowan, P., \& Cooper, S. (2011). Developing quality in female high-technology entrepreneurs' networks. International Journal of Entrepreneurial Behavior \& Research, 17(6), 588-606.

Henry, C., Foss, L., \& Ahl, H. (2015). Gender and entrepreneurship research: A review of methodological approaches. International Small Business Journal, 34(3), 217-241.

Jennings, J. E., \& Brush, C. G. (2013). Research on women entrepreneurs: challenges to (and from) the broader entrepreneurship literature? Academy of Management Annals, 7(1), 663-715.

Kanter, R. M. (1993). Men and women of the corporation. Basic Books.

Karataş-Özkan, M., \& Chell, E. (2015). Gender inequalities in academic innovation and enterprise: a Bourdieuian analysis. British Journal of Management, 26(1), 109-125.

Kirkwood, J. (2009). Motivational factors in a push-pull theory of entrepreneurship. Gender in Management: An International Journal, 24(5), 346-364.

Klofsten, M., \& Jones-Evans, D. (2000). Comparing academic entrepreneurship in Europe-the case of Sweden and Ireland. Small Business Economics, 14(4), 299-309.

Kuschel, K., \& Lepeley, M. T. (2016). Women start-ups in technology: literature review and research agenda to improve participation. International Journal of Entrepreneurship and Small Business, 27(2-3), 333-346.

Kuschel, K., Lepeley, M. T., Espinosa, F., \& Gutiérrez, S. (2017). Funding challenges of Latin American women start-up founders in the technology industry. Cross Cultural \& Strategic Management, 24(2), 310-331.

Lee, I. H., \& Marvel, M. R. (2014). Revisiting the entrepreneur gender-performance relationship: a firm perspective. Small Business Economics, 42(4), 769-786.

Lindholm Dahlstrand, Å., \& Politis, D. (2013). Women business ventures in Swedish university incubators. International Journal of Gender and Entrepreneurship, 5(1), 78-96.

Lorber, J. (2000). Using gender to undo gender: A feminist degendering movement. Feminist Theory, 1(1), 79-95.

Marlow, S., \& McAdam, M. (2011). Analyzing the influence of gender upon high-technology venturing within the context of business incubation. Entrepreneurship Theory and Practice, 36(4), 655-676.

Marlow, S., \& McAdam, M. (2012). Gender and entrepreneurship: Advancing debate and challenging myths; exploring the mystery of the under-performing female entrepreneur. International Journal of Entrepreneurial Behavior \& Research, 19(1), 114-124.

Marlow, S., \& McAdam, M. (2015). Incubation or induction? Gendered identity work in the context of technology business incubation. Entrepreneurship Theory and Practice, 39(4), 791-816. 
Martin, L. M., \& Tiu Wright, L. (2005). No gender in cyberspace? Empowering entrepreneurship and innovation in female-run ICT small firms. International Journal of Entrepreneurial Behavior \& Research, 11(2), 162-178.

Martin, L., Wright, L., Beaven, Z., \& Matlay, H. (2015). An unusual job for a woman? Female entrepreneurs in scientific, engineering and technology sectors. International Journal of Entrepreneurial Behavior \& Research, 21(4), 539-556.

McGowan, P., Redeker, C. L., Cooper, S. Y., \& Greenan, K. (2012). Female entrepreneurship and the management of business and domestic roles: Motivations, expectations and realities. Entrepreneurship \& Regional Development, 24(1-2), 53-72.

Murray, F., \& Graham, L. (2007). Buying science and selling science: gender differences in the market for commercial science. Industrial and Corporate Change, 16(4), 657-689.

Neeley, L., \& Van Auken, H. (2010). Differences between Female and Male Entrepreneurs' use of Bootstrap Financing. Journal of Developmental Entrepreneurship, 15(01), 19-34.

Neill, S., Metcalf, L., \& York, J. L. (2014). Seeing what others miss: A study of women entrepreneurs in high-growth startups. Entrepreneurship Research Journal, 5(4), 293-322.

Newbert, S. L. (2007). Empirical research on the resource-based view of the firm: an assessment and suggestions for future research. Strategic Management Journal, 28(2), 121-146.

O'Connor, V., Hamouda, A., McKeon, H., Henry, C., \& Johnston, K. (2006). Co-entrepreneurial ventures: A study of mixed gender founders of ICT companies in Ireland. Journal of Small Business and Enterprise Development, 13(4), 600-619.

OECD (2018), Transformative technologies and jobs of the future.

OECD (2017), Policy Brief on Women’s Entrepreneurship.

Ogbor, J. O. (2000). Mythicizing and reification in entrepreneurial discourse: Ideology-critique of entrepreneurial studies. Journal of Management Studies, 37(5), 605-635.

Orser, B., \& Hogarth-Scott, S. (2002). Opting for growth: gender dimensions of choosing enterprise development. Canadian Journal of Administrative Sciences, 19, 284-300.

Orser, B., Riding, A., \& Stanley, J. (2012). Perceived career challenges and response strategies of women in the advanced technology sector. Entrepreneurship \& Regional Development, 24(1-2), 73-93.

Osagie, E. R., Wesselink, R., Blok, V., Lans, T., \& Mulder, M. (2016). Individual competencies for corporate social responsibility: A literature and practice perspective. Journal of Business Ethics, 135(2), 233-252. 
Pascher, U., Roski, M., \& Halbfas, B. (2015). Entrepreneurial aspirations and start-up motives of women chemists in Germany. International Journal of Gender and Entrepreneurship, 7(3), 272290.

Pittaway, L., \& Cope, J. (2007). Entrepreneurship education: a systematic review of the evidence. International Small Business Journal, 25(5), 479-510.

Poggesi, S., Mari, M., \& De Vita, L. (2017). Women entrepreneurs and work-family conflict: an analysis of the antecedents. International Entrepreneurship and Management Journal, 1-24. https://doi.org/10.1007/s11365-017-0484-1.

Poggesi, S., Mari, M., \& De Vita, L. (2016). What's new in female entrepreneurship research? Answers from the literature. International Entrepreneurship and Management Journal, 12(3), 735-764.

Poggesi, S., Mari, M., \& De Vita, L. (2015). Family and Work-Life Balance Mechanisms: What is Their Impact on the Performance of Italian Female Service Firms? The International Journal of Entrepreneurship and Innovation, 16(1), 43-53.

Powell, G. N., \& Eddleston, K. A. (2013). Linking family-to-business enrichment and support to entrepreneurial success: do female and male entrepreneurs experience different outcomes? Journal of Business Venturing, 28(2), 261-280.

Robb, A. M., \& Coleman, S. (2010). Financing strategies of new technology-based firms: a comparison of women-and men-owned firms. Journal of Technology Management \& Innovation, $5(1), 30-50$.

Robb, A. M., \& Watson, J. (2012). Gender differences in firm performance: Evidence from new ventures in the United States. Journal of Business Venturing, 27(5), 544-558.

Rodríguez-Gulías, M. J., Fernández-López, S., \& Rodeiro-Pazos, D. (2018). Gender differences in growth of Spanish university spin-offs. Gender in Management: An International Journal, 33(2), 86-103.

Rosa, P., \& Dawson, A. (2006). Gender and the commercialization of university science: academic founders of spinout companies. Entrepreneurship and Regional Development, 18(4), 341-366.

Rousseau, D. M., Manning, J., \& Denyer, D. (2008). 11 evidence in management and organizational science: Assembling the field's full weight of scientific knowledge through syntheses. The Academy of Management Annals, 2(1), 475-515.

Rothaermel, F. T., Agung, S. D., \& Jiang, L. (2007). University entrepreneurship: a taxonomy of the literature. Industrial and Corporate Change, 16(4), 691-791. 
Smeding, A. (2012). Women in science, technology, engineering, and mathematics (STEM): An investigation of their implicit gender stereotypes and stereotypes' connectedness to math performance. Sex Roles, 67(11-12), 617-629.

Solnørdal, M., \& Foss, L. (2018). Closing the energy efficiency gap-A systematic review of empirical articles on drivers to energy efficiency in manufacturing firms. Energies, 11(3), 518.

Thorpe, R., Holt, R., Macpherson, A., \& Pittaway, L. (2005). Using knowledge within small and medium-sized firms: a systematic review of the evidence. International Journal of Management Reviews, 7(4), 257-281.

Thursby, J. G., \& Thursby, M. C. (2005). Gender patterns of research and licensing activity of science and engineering faculty. The Journal of Technology Transfer, 30(4), 343-353.

Tranfield, D., Denyer, D., \& Smart, P. (2003). Towards a methodology for developing evidenceinformed management knowledge by means of systematic review. British Journal of Management, 14(3), 207-222.Welter, F., Baker, T., Audretsch, D. B., \& Gartner, W. B. (2017). Everyday entrepreneurship - a call for entrepreneurship research to embrace entrepreneurial diversity (DOI: 10.1111/etap.12258).

Wickware, P. (1997). Along the leaky pipeline. Nature, 390(6656), 202-203. 
Appendix - The final dataset*

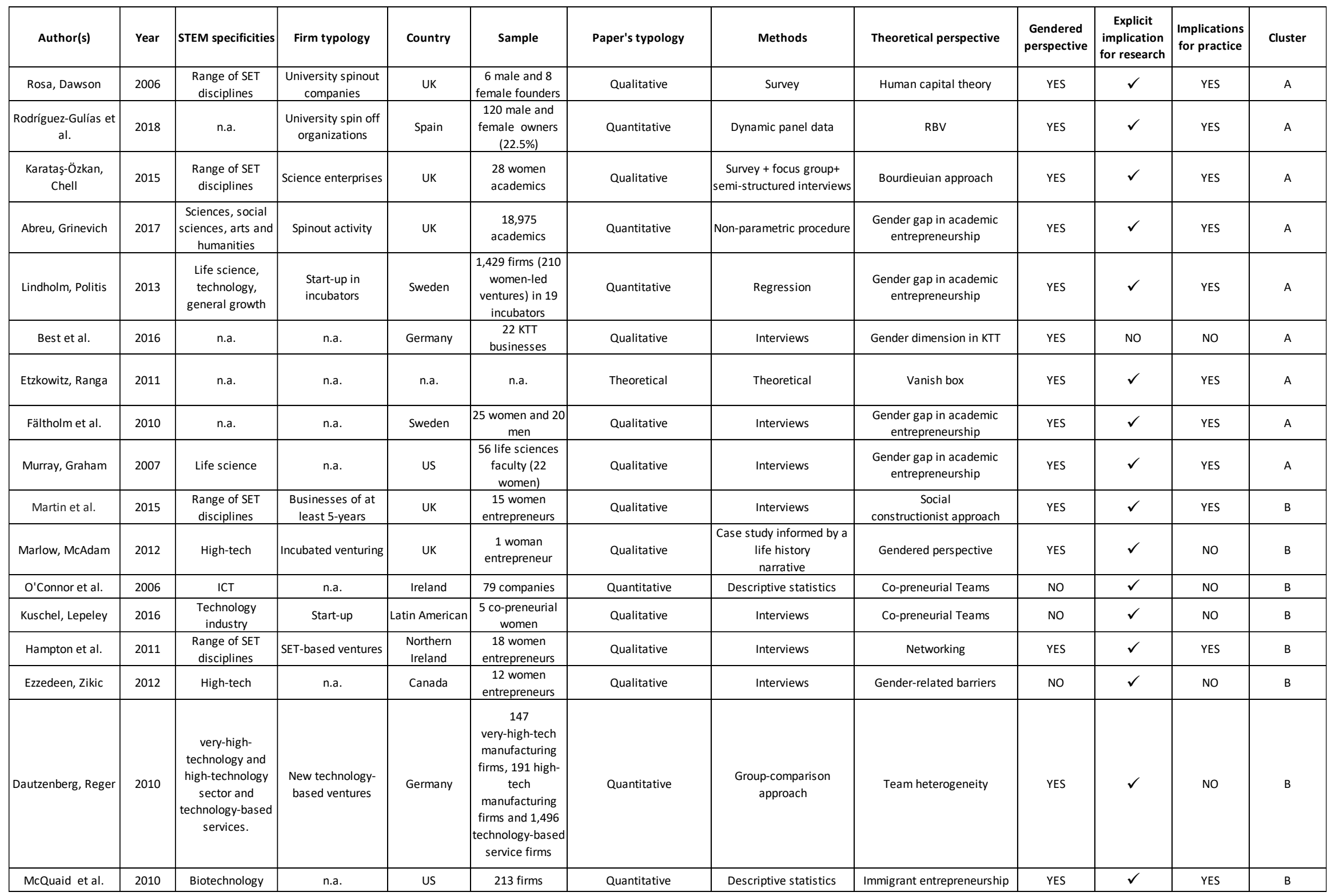




\begin{tabular}{|c|c|c|c|c|c|c|c|c|c|c|c|c|}
\hline Hampton et al. & 2009 & $\mid \begin{array}{c}\text { Technology-based } \\
\text { sectors }\end{array}$ & \begin{tabular}{|c|} 
Firms at different \\
stages in the \\
development of \\
their technology- \\
based enterprise \\
\end{tabular} & $\begin{array}{l}\text { Northern } \\
\text { Ireland }\end{array}$ & $\begin{array}{c}18 \text { women } \\
\text { entrepreneurs }\end{array}$ & Qualitative & Interviews & Networking & NO & $\checkmark$ & YES & B \\
\hline Marlow, McAdam & 2015 & $\begin{array}{c}\text { hlgh-tech business } \\
\text { incubators }\end{array}$ & Business incubators & UK & $\begin{array}{l}4 \text { women } \\
\text { entrepreneurs }\end{array}$ & Qualitative & Interviews & Identity work & YES & $\checkmark$ & YES & B \\
\hline Buche, Scillitoe & 2007 & $\begin{array}{c}\text { New technology- } \\
\text { based ventures }\end{array}$ & $\begin{array}{l}\text { New technology- } \\
\text { based ventures }\end{array}$ & US and Finland & \begin{tabular}{|c|}
54 NTBVs within \\
19 different \\
technology \\
incubators
\end{tabular} & Quantitative & Regression & Networking & YES & $\checkmark$ & YES & B \\
\hline Eriksson et al. & 2008 & ICT & $\begin{array}{c}\text { Small } \\
\text { software service } \\
\text { companies }\end{array}$ & Finland & 4 companies & Qualitative & Ethnographic research & $\begin{array}{c}\text { Social } \\
\text { constructionist approach }\end{array}$ & YES & $\checkmark$ & YES & B \\
\hline Orser et al. & 2012 & High-tech & n.a. & Canada & 115 women & Qualitative & Survey & Gender-related barriers & YES & $\checkmark$ & YES & B \\
\hline Pascher et al. & 2015 & Chemistry & Start-up & Germany & $\begin{array}{c}65 \text { business } \\
\text { founders in the } \\
\text { chemical industry }\end{array}$ & Qualitative & Interviews & Motivation & YES & $\checkmark$ & NO & B \\
\hline Robb, Coleman & 2010 & $\begin{array}{c}\text { New technology- } \\
\text { based firms }\end{array}$ & n.a. & various & $\begin{array}{c}\text { more than } 500 \\
\text { technology-based } \\
\text { firms }\end{array}$ & Quantitative & Regression & Financing strategies & YES & $\checkmark$ & NO & B \\
\hline Kuschell et al. & 2017 & $\begin{array}{l}\text { Technology } \\
\text { industry }\end{array}$ & Start-up & Chile & $\begin{array}{l}20 \text { women } \\
\text { entrepreneurs } \\
\text { and start-up } \\
\text { female owners }\end{array}$ & Qualitative & Survey and interviews & Financing strategies & YES & $\checkmark$ & YES & B \\
\hline Dautzenberg & 2012 & $\begin{array}{c}\text { Technology-based } \\
\text { sectors }\end{array}$ & various & Germany & \begin{tabular}{|c|}
593 firms in very- \\
high-tech- \\
manufacturing, \\
886 firms in high- \\
tech \\
manufacturing, \\
and 4,822 firms \\
in technology- \\
based service \\
industries \\
\end{tabular} & Quantitative & Regression & Gendered and technology & YES & $\checkmark$ & NO & B \\
\hline Gicheva, Link & 2013 & $\begin{array}{c}\text { Technology-based } \\
\text { sectors }\end{array}$ & n.a. & US & 323 observations & Quantitative & Probit/tobit models & Financing strategies & YES & n.a. & NO & B \\
\hline Martin, Wright & 2005 & ICT & ICT firms & UK & $\begin{array}{c}10 \text { Female } \\
\text { entrepreneurs }\end{array}$ & Qualitative & $\begin{array}{c}\text { Case studies and thematic } \\
\text { analysis }\end{array}$ & Networking & YES & $\checkmark$ & NO & B \\
\hline Lee, Marvel & 2014 & $\begin{array}{c}\text { High-tech } \\
\text { manufacturing } \\
\text { industries } \\
\end{array}$ & n.a. & Korea & $\begin{array}{l}4,540 \text { Korean } \\
\text { ventures }\end{array}$ & Quantitative & Regression & Gender and performance & YES & $\checkmark$ & YES & B \\
\hline Neill et al. & 2014 & $\begin{array}{c}\text { High-growth start- } \\
\text { ups }\end{array}$ & Start-up & US & $\begin{array}{l}165 \text { women } \\
\text { entrepreneurs }\end{array}$ & Quantitative & Structural models & Perception of opportunity & YES & $\checkmark$ & YES & B \\
\hline Alakaleek, Cooper & 2018 & $\begin{array}{c}\text { Technology-based } \\
\text { sectors }\end{array}$ & n.a. & Jordan & $\begin{array}{c}16 \text { women } \\
\text { entrepreneurs }\end{array}$ & Qualitative & Interviews & Networking & NO & $\checkmark$ & YES & B \\
\hline Bendell et al. & 2018 & $\begin{array}{l}\text { High-tech } \\
\text { incubators }\end{array}$ & $\begin{array}{l}\text { High-growth } \\
\text { ventures } \\
\text { operating in high- } \\
\text { technology } \\
\text { incubators }\end{array}$ & US & $\begin{array}{c}383 \text { male and } \\
\text { female founders }\end{array}$ & Quantitative & Regression & Self-leadership & YES & $\checkmark$ & NO & B \\
\hline
\end{tabular}

*(A) refers to the $1^{\text {st }}$ cluster "Academic women entrepreneurs in STEM fields"; (B) refers to the $2^{\text {nd }}$ cluster "Non-academic women entrepreneurs in STEM fields". 